\title{
Response variability for humans receiving continuous, intermittent, or no positive experimenter feedback*
}

\author{
DAVID A. ECKERMAN and ROBERT VREELAND \\ University of . Vorth Carolina. Chapel Hill. I.C. 27514
}

Undergraduates made an " $x$ " on a series of blank sheets of paper in a study designated as an "acquisition of a manual skill." Each mark was designated as "correct" or "incorrect" by the E, but according to a pre-fixed order rather than according to characteristics of the response. Variability in location of the mark on the page was lowest during trials in which each mark was "correct," intermediate when an average of every third mark was "correct," and highest when no marks were "correct." Increased variability during these latter two conditions is attributable to trials following marks which were "incorrect." Evidence demonstrating control of response variability for human Ss by the schedule of $E$ feedback is thus provided.

Several studies with both humans and nonhumans have demonstrated that variability of response topography increases when the schedule of reinforcement is shifted from continuous reinforcement to either intermittent reinforcement or extinction (e.g.. Antonitis, 1951: Lane \& Shinkman. 1963: Ferraro \& Branch. 1968: Eckerman \& Lanson, 1969). Two notable exceptions to this general finding. however, have been found. Herrnstein (1961) observed decreased variability in location of pigeon's keypeck responding following a shift from continuous reinforcement to a variable interval 3-min schedule of reinforcement. Gates \& Fixsen (1968) found that the variability in buttonpress location of retarded children (within an eight-key array) was (1) lowest during extinction. (2) intermediate during intermittent reinforcement, and (3) highest during continuous reinforcement. The present study provides further data with human Ss, confirming the general finding of increased response variability during intermittent schedules of positive $E$ feedback or extinction. This finding is extended, in the present study, to a trials procedure rather than a free-operant procedure, and sequential dependencies were analyzed. Since no test of rate-increasing properties of the response outcomes was made in the present study, the outcomes are labeled "positive experimenter feedback" rather than "reinforcers."

\section{METHOD}

\section{Apparatus}

No specialized equipment was required for the study. Pencils and $8: 2 \times 11$ in white paper were used for the Ss to make responses. Yellow and white cards were used as response feedback.

*This work was supported by Grant $\mathrm{MH}-15540$ from the National Institute of Mental Health to the first author. Reprints may be obtained from David A. Eckerman. Department of Psychology. University of North Carolina. Chapel Hill. N.C. 27514 .

\section{Subjects}

Fourteen undergraduate students in a summer session introductory psychology course served as Ss. They received one-fifth of their course requirement for experimental participation hours for serving.

\section{Procedure}

A S. upon arriving at the faculty office. was seated at a desk and told that he was participating in an experiment concerning the acquisition of a manual skill. Then the $S$ was told that. "When I hand you this clipboard, you will make one mark on the attached paper with this pencil. The mark I want you to make is an ' $x$.' You may put this mark anywhere on the paper that you like. Some of your marks I will consider as correct. some as incorrect. You will know whether you have been correct or incorrect by the color of the card I will hand you after each trial." A yellow card indicated "correct." a white card "incorrect." After each mark. the E replaced the paper and handed the clipboard back (about one trial per $15 \mathrm{sec}$ ).

Each $S$ received a total of 61 trials. The order of positive (yellow card) and negative (white card) feedback was predetermined and identical for all Ss. The first five trials (labeled "practice trials" to the S) all provided yellow cards. At the start of the sixth trial. the S was told. "Now I will start judging your marks as correct or incorrect." Yellow cards were given following each of the next five trials $(6-10)$. This condition will be called CRF 1. During Trials 10-31. yellow cards were given following Trials 14.16.17. 22. 24. 30. and 31. an average of once every three trials. This condition will be called VR 3 . During Trials $32-51$. no yellow cards were given (EXT). And. during Trials 52-61. yellow cards were given following each trial (CRF 2).

Ss were then asked to answer orally the following questions: (1) What do you think was the attribute of your marks that I was developing into a skill? (2) Do you think that the location of the mark was at all important? (3) Do you think that the order of yellow and white cards was pre-fixed and did not have anything to do with your marks? Ss were then debriefed and pledged to silence.

\section{RESULTS}

Variability in response location was typically lower during CRF 1 and CRF 2 than during VR 3 or EXT (Fig. 1). Panel A of Fig. 1 shows these effects for variability in the distance of responses from the mean location in each condition (hereafter called $R$ ). In calculating $R$. mean location for each condition was calculated for each $\mathrm{S}$. The mean distance of each response from this average location was then determined for each condition and for each S. Finally. a median value for each condition was obtained across Ss. A Kendall's W test on ranks confirmed that variability for the two CRF conditions was reliably lower than that for either VR or EXT and that VR variability was lower than that for EXT $(p<.05)$. Tests for variability of response location across Cartesian $\mathrm{x}$ and $\mathrm{y}$ dimensions also indicated that these effects were statistically reliable $(\mathrm{p}<.01$ in both cases). Thus. dispersion of response location was affected by the schedule of feedback. The 


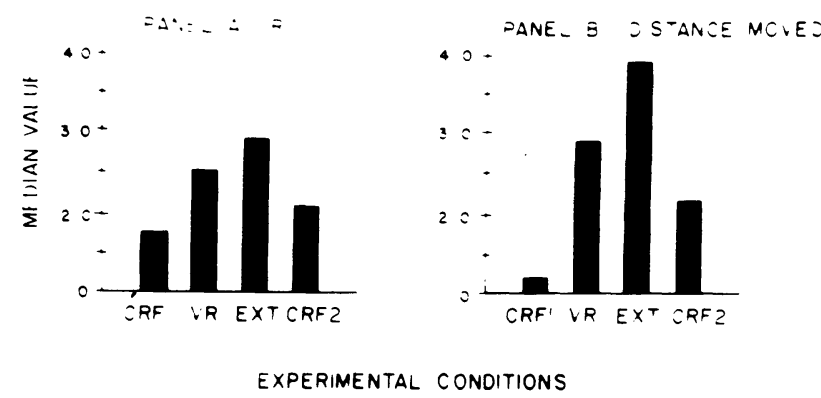

Fig. 1. Median response dispersion (Panel A. see text for definition of $\mathbf{R}$ ) and median distance moved (Panel B) for the 14 $\mathrm{Ss}$ in each condition of the experiment. Both measures in inches.

average response location did not change from condition to condition.

A second measure of response variability is shown in Panel B of Fig. 1: mean distance moved from Trial $n$ to Trial $n+1$. Although the pattern shown is similar to that for the $\mathrm{R}$ measure. a Kendall's $\mathrm{W}$ test shows the results to be unreliable across Ss $(0.30 . p<.20)$. Thus, greater dispersion within a condition $(R)$ does not necessarily imply greater movement from trial to trial.

While the distance-moved measure showed less orderly change from individual to individual across experimental conditions. it does provide a means of evaluating intracondition changes and hence merits further inspection. Figure 2 presents changes in distance moved within VR and EXT conditions. For both conditions,

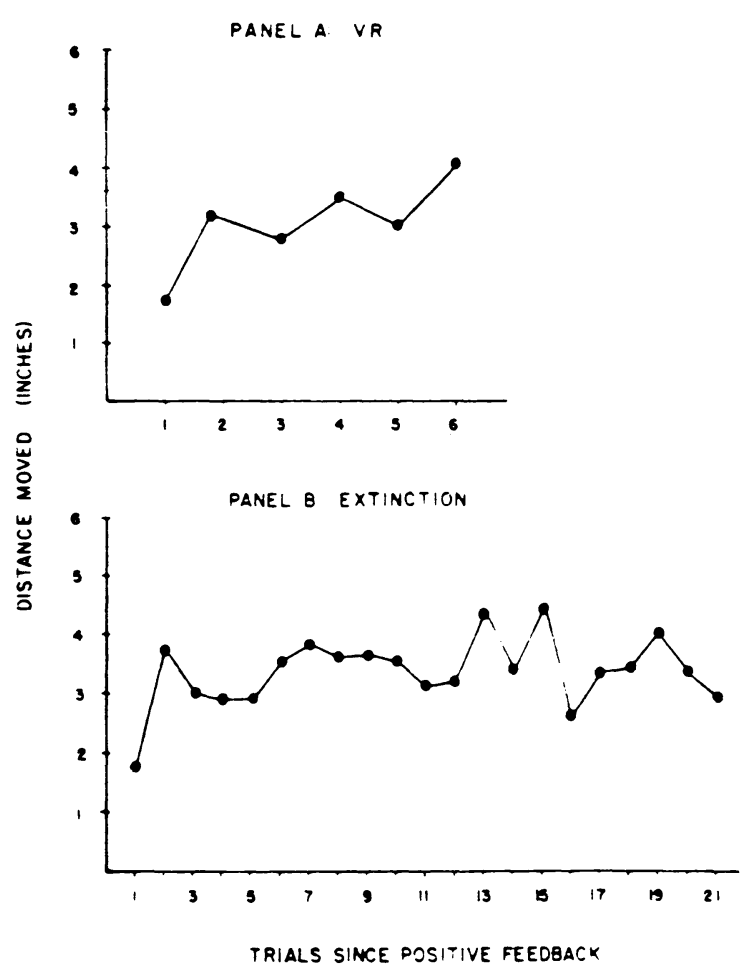

Fig. 2. Median distance moved for the $14 \mathrm{Ss}$ as a function of trials since positive feedback in VR (Panel A) and EXT (Panel B) conditions. Distance moved in inches. distance moved is shown as a function of trials since positive feedback.

For VR. distance moved increased across consecutive negative feedback trials. This effect was statisticaliy reliable (analysis of variance on mean distance moved produced $F=3.37$. $\mathrm{df}=5.78$ : and $\mathrm{p}<.01$ ).

For EXT. the first trial showed lower variability than subsequent trials (as expected from the VR data). but subsequent trials did not produce orderly changes in location. The overall EXT effect is therefore nonsignificant $(F=0.43 . \mathrm{df}=20.270: \mathrm{p}>.5)$.

Inspection of individual Ss performance showed that 6 of the 14 conformed exactly to the rankings shown in Fig. 1 (both CRF 1 and CRF 2 less than both VR 3 and EXT). It is noteworthy that these Ss showed a strong direct relationship between distance moved and trials since positive feedback in both VR and EXT conditions. For other Ss. this relationship was not clear.

In answering the questions following the experiment. few Ss suggested that there was little relation between properties of their response and obtaining a yellow card. Of the $10 \mathrm{Ss}$ for whom answers are available (four protocols were lost). only 1 proposed such a possibility in answer to Question 1. and only 6 accepted the possibility by Question 3 (for "at least some part of the experiment"). Eight of these 10 Ss suggested that location of the response was critical for obtaining yellow cards. One $\mathrm{S}$ suggested that another response property (size) was critical. and 1 had "found us out."

\section{DISCUSSION}

The present study confirms the hypothesis that human Ss show greater variability in response location under intermittent schedules of positive feedback. Further. greater variability was shown during EXT than under VR 3. Since "distance moved" is comparable for (a) CRF conditions. (b) trials following positive feedback during VR 3 . and $(c)$ the first trial of EXT. the data suggest that the increased variability during VR and EXT derives from postnegative-feedback trials.

The present data also offer further extensions of the control of variability to (1) a short-term situation (several trials rather than several days). (2) a "field" response rather than pressing discrete buttons. (3) a "trials" rather than "free-operant" procedure. (4) a rather small difference in schedule ICRF is VR 3). and (5) conditioned positive feedback (yellow cards) rather than the probably more potent reinforcers of money (Lane \& Shinkman. 1963) or edibles (other studies).

Special note might be given to Point 3 above. By using a trials rather than free-operant procedure. sequential dependencies between responses were undoubtedly altered. Blough (1963) has stressed the control exerted by a response upon closely following responses in free-operant situations. For example. such responses show little control by external stimuli. In the present study, such response-response dependencies should be reduced by the trials procedure. Lndoubtedly the dependency of response location on trials since positive feedback is a function of procedures that manipulate response-response dependencies. A further and related factor is rate dependency. The possibility of rate-dependent (rather than schedule-dependent) control of variability is eliminated by use of a trials procedure.

\section{REFERENCES}

Antonitis. J. J. Response variability in the white rat during conditioning. extinction. and reconditioning. Journal of Experimental Psychology. 1951. 42, 273-281. 
Blough. D. Interresponse time as a function of continuous variables: A new method and some data. Journal of the Experimental Analysis of Behavior, 1963. 6. 237-246.

Eckerman, D. A.. \& Lanson. R. N. Variability of response location for pigeons responding under continuous reinforcement, intermittent reinforcement, and extinction. Journal of the Experimental Analysis of Behavior, 1969, 12 73-80

Ferraro. D. P., \& Branch, K. H. Variability of response location during regular and partial reinforcement. Psychological Reports. $1968,23,1023-1031$.
Gates, J. J., \& Fixsen. D. Response variability in retarded children. Journal of Experimental Child Psychology. 1968.6. 306-320.

Herrnstein, R. J. Stereotypy and intermittent reinforcement. Science, $1961,133,2067-2069$

Lane. H., \& Shinkman, P. G. Methods and findings in an analysis of a vocal operant. Journal of the Experimental Analysis of Behavior, $1963,6,179-188$.

(Rece:ved for publication June 11. 1973.)

\section{Effects of partial reinforcement $(25 \%)$ in an au toshaping procedure*}

\section{FERNANDO A. GONZALEZ \\ The Lniversity of . Vorth Carolina. Chapel Hill. I.C. 27514}

For three pigeons exposed to an autoshaping procedure, every signal ( $9-\mathrm{sec}$ transillumination of the response key) was followed by a $4-\mathrm{sec}$ access to grain. For three other pigeons, only $25 \%$ of the signals were paired with food. Total number of signal-food pairings was matched across groups. Relative to $100 \%$ reinforcement, $25 \%$ reinforcement delayed the development of asymptotic performance, and resulted in lower asymptotic proportions of signals with responses as well as longer response latencies during the signals.

If a pigeon's response key is repeatedly illuminated for several seconds preceding response-independent presentations of grain. keypecking will eventually occur during the signal. This phenomenon has been labeled "autoshaping" (Brown \& Jenkins. 1968). The autoshaping procedure is formally similar to the Pavlovian conditioning procedure. The fact that keypecking, a complex skeletal response directed at a feature of the environment, can be engendered and maintained by response-independent presentations of grain has aroused considerable interest (e.g.. Bolles, 1972: Moore. 1971: Seligman, 1970: Shettleworth. 1971: Staddon \& Simmelhag. 1971).

* This research was supported by NIMH Gran 5 R01MH 15468-03 to Vincent M. LoLordo, who sponsors this paper and takes full editorial responsibility for it. Preparation of the manuscript was supported by $\tau$.S. Public Health Serrice Grant .IH 07084. Reprints may be obtained from the author. Harvard Medical School. New England Regional Primate Research Center. Southborough. Mass. 01772.
A number of experiments have been performed to determine how the principles of Pavlovian conditioning and of operant conditioning can account for autoshaping. The results of experiments by Williams \& Williams (1969). Gamzu \& Williams (1971). Moore (1971), and Schwartz \& Williams (1972a b) suggest that while adventitious pairings of keypecking and food may modulate some of the characteristics of the keypecking responses which occur during the signal. the differential pairing of the signal with food is the more important determinant of authoshaping.

The present experiment was performed to assess the effect of "partial reinforcement" on the acquisition of keypecking under an autoshaping procedure. In Pavlovian conditioning experiments. partial reinforcement has usually referred to experimental conditions in which the probability of UCS immediately following the CS is greater than zero and less than one. but is zero at other times. Relative to $100 \%$ reinforcement. partial reinforcement has been reported to retard acquisition and to result in lower asymptotic levels of the CR in human eyeblink conditioning (cf. Ross \& Hartman. 1965). However. the effects of partial reinforcement in Pavlovian conditioning experiments with animals have been inconsistent (cf. Gormezano \& Moore. 1969. p. 166).

Williams \& Williams (1968) and Schwartz \& Williams (1972a.b) have demonstrated that keypecking can be established and maintained by autoshaping procedures in which the signal is only occasionally paired with food. However. there have been no reported comparisons of the course of acquisition of autoshaping under continuous and partial reinforcement schedules. The present experiment was designed to fill the gap. 